\title{
Analisis Kinerja Lalu Lintas Simpang Tak Bersinyal untuk Penentuan Tingkat Pelayanan di Jalan Klampis Jaya Surabaya
}

\author{
Analysis of Traffic Performance at the Non-Signalized Intersection to Determine the Level of \\ Service on the Klampis Jaya Road, Surabaya
}

Dwi Prastya Nurcahaya ${ }^{1^{*}}$, R Endro Wibisono ${ }^{2}$

${ }^{1,2}$ Program Studi Teknologi Rekayasa Trasnportasi, Universitas Negeri Surabaya

\begin{tabular}{l}
\hline \hline ARTICLE INFO \\
\hline Article history: \\
DOI: \\
10.30595/pspfs.v1i.151 \\
Submitted: \\
June 28, 2021 \\
Accepted: \\
July 10, 2021 \\
Published: \\
Oct 31, 2021 \\
\hline
\end{tabular}

Keywords:

Non-Signalized Intersections, Service Level, Traffic Volume

\begin{abstract}
Klampis Jaya Road, Surabaya City, has a fairly heavy traffic flow, especially during working hours. This resulted in congestion on Klampis Jaya Road and not a few motorists who violated traffic regulations such as turning around Mleto Road. This study aimed to determine the current traffic flow performance and in 2024 at the intersection on Klampis Jaya Road, Surabaya City, predicted the traffic flow performance around the road and intersection on Klampis Jaya Road Surabaya City. The research method used was non-signalized intersection analysis using the Indonesian Road Capacity Manual. The calculation of the traffic performance of the four intersections in Klampis Jaya showed the Degree of Saturation (DS) and Service Level (TP) of each intersection. Traffic performance for the four intersections in 2021 was DS $=0.752$ and $\mathrm{TP}=\mathrm{C}$ (Enough), with the characteristics of stable traffic flow, was restricted movement. The traffic performance for the four intersections in 2024 was DS $=0.95$ and TP $=$ D (Less), with the characteristics of traffic flow stable movement being limited.
\end{abstract}

This work is licensed under a Creative Commons Attribution 4.0 International License.

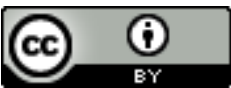

Corresponding Author:

Dwi Prastya Nurcahaya

Program Studi Teknologi Rekayasa Trasnportasi, Universitas Negeri Surabaya

J1. Kampus Unesa Ketintang, Surabaya, Kode Pos 60231

Email: dwi.19007@mhs.unesa.ac.id

\section{PENDAHULUAN}

Jalan merupakan salah satu jenis prasarana transportasi darat yang memegang peranan penting bagi pengembangan suatu daerah. Kondisi jalan yang baik akan memudahkan mobilitas penduduk dalam mengadakan kegiatan ekonomi dan kegiatan sosial lainnya.Kegiatan tersebut kemudian memicu adanya perjalanan atau pergerakan di masyarakat menggunakan tata guna lahan di daerah sekitar atau tempat tujuan kegiatan. Pergeran bukan hanya dilakukan oleh manusia, namun dapat terjadi barang dan kendaraan sehingga terjadi ikatan yang dinamakan interaksi. Menurut Kamus Besar Bahasa Indonesia Interaksi artinya saling melakukan aksi, berhubungan, dan saling mempengaruhi. Kegiatan interaksi antara manusia dengan manusia, manusia dengan barang dan manusia dengan kendaraan akan menghasilkan arus lalu lintas.Menurut Manual Kapasitas Jalan Indonesia arus lalu lintas adalah jumlah kendaraan bermotor yang melalui titik pada jalan persatuan waktu dinyatakan dalam kend/jam, smp/jam atau LHRT (Lalu lintas Harian Rata-rata Tahunan)

Klampis Jaya Kota Surabaya merupakan salah satu lokasi yang memiliki arus lalu lintas cukup padat terutama pada jam-jam pulang kerja. Hal tersebut mengakibatkan kemacetan di jalan Klampis Jaya dan tidak sedikit pengendara yang melanggar peraturan lalu lintas seperti, putar balik arah disekitar Jalan Mleto. Untuk mengatasi kemacetan lalu lintas maka, diperlukan survey untuk menetukan suatu sistem penentuan fase dan pengaturan lalu lintas yang baik 
agar memberikan kelancaran, kenyamanan dan keselamatan bagi pengguna jalan. Sistem penentuan fase dan pengaturan lalu lintas biasanya digunakan atau diterapkan pada lokasi-lokasi dimana ada persimpangan jalan atau yang sering mengalami kemacetan. Seperti halnya Jalan Klampis Jaya ini.

Dengan survey tersebut diharapkan adanya pembenahan permasalahan arus lalu lintas terutama dalam kondisi tahap pertumbuhan urbanisasi yang tinggi akibat laju pertumbuhan ekonomi di suatu wilayah perkotaan yang pesat, Sehingga kebutuhan penduduk untuk melakukan pergerakan pun menjadi semakin meningkat, terutama dalam hal mobilisasi pergerakannya. Jumlah penduduk yang tinggal di daerah perkotaan di Indonesia salah satunya di Kota Surabaya yang semakin meningkat dari tahun ke tahun akibat tingginya tingkat urbaisasi.

Untuk hal itu tujuan penelitian yang perlu dilakukan untuk menjawab permasalahan arus lalu lintas yang terjadi di Jalan Klampis Jaya Kota Surabaya yaitu untuk memprediksi kinerja arus lalu lintas di sekitar ruas jalan dan simpang pada Jalan Klampis Jaya Kota Surabaya; untuk melakukan manajemen kinerja arus lalu lintas dan rekayasa arus lalu lintas pada ruas jalan dan simpang di sekitar lokasi Jalan Klampis Jaya Kota Surabaya; untuk mengetahui kinerja arus lalu lintas saat ini dan tahun 2024 di beberapa ruas jalan dan simpang di Jalan Klampis Jaya Kota Surabaya.

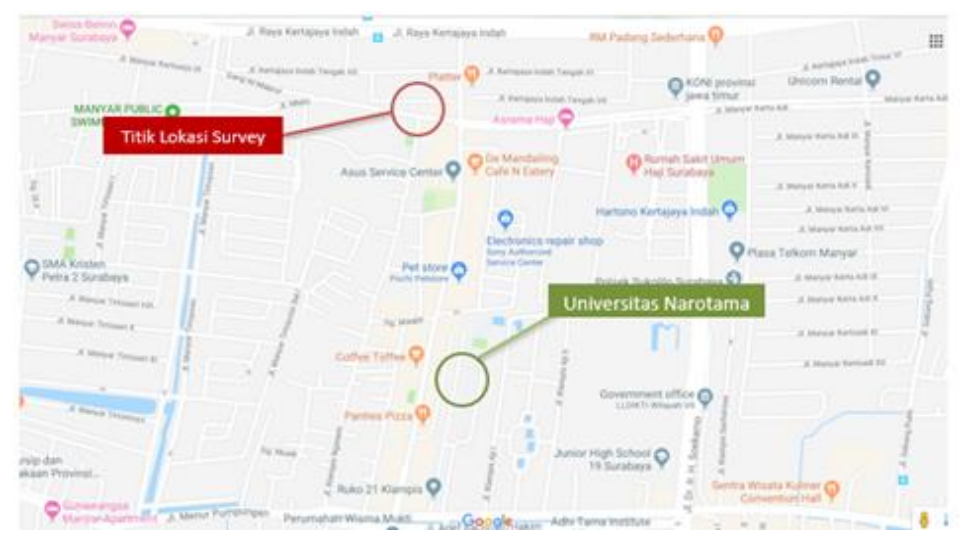

Gambar 1. Master Plant Area

\section{METODE PENELITIAN}

Pada suatu penelitian tidak lepas dari metode yang digunakan. Untuk itu agar mendapatkan suatu penelitian yang sesuai dengan tujuan kita diperlukan adanya metode penelitian tahap persiapan pada tahap persiapan kegiatan yang akan dilakukan diantaranya: Studi Literatur

Pada tahap studi literatur ini, pihak Konsultan akan mempelajari beberapa referensi terkait dengan studi ini sebagai dasar untuk melangkah ke tahapan berikutnya yakni pengumpulan dan analisis data.

Survey Pendahuluan, pada survey pendahuluan ini, pihak Konsultan akan melakukan observasi awal di beberapa lokasi kritis ruas jalan dan simpang di kawasan Jalan simpang Klampis Jaya-Manyar. Dari observasi awal diharapkan bisa ditentukan lokasi titik survei pengumpulan data primer.

Tahap Pengumpulan Data Survey Inventaris Geometrik Ruas Jalan dan SimpangHasil akhir survey inventaris geometrik ruas jalan dan simpang adalah untuk mengetahui kapasitas ruas jalan dan simpang. Alat yang digunakan untuk mengukur adalah bisa menggunakan rollmeter atau walking measure meter. Adapun yang diukur/diinventaris adalah lebar ruang manfaat jalan (rumaja). Khusus untuk survey inventaris geometrik sebuah simpang, pengukuran lebar dilakukan tiap lajur ruas jalan yang merupakan lengan pendekat simpang.

Survey Pencacahan Lalu Lintas Kendaraan Data primer mengenai kondisi lalu lintas jaringan jalan di sekitar lokasi proyek didapatkan dengan melakukan pencacahan lalu lintas kendaraan yang lewat (traffic counting survey). Secara teknis, pelaksanaan survey traffic counting dilakukan selama 2 jam dan 1 shift waktu pengamatan. Survey dilakukan pada pukul 17.00 - 19.00. Adapun perlatan yang dibutuhkan untuk melakukan survey traffic counting adalah dengan menggunakan counter, jam tangan dan peralatan tulis.

Survey Pencacahan Keluar Masuk Kendaraan di Pelabuhan Tanjung Perak. Survey pencacahan kendaraan yang keluar masuk Pelabuhan Tanjung Perak bertujuan untuk mengetahui besar tarikan/produksi perjalanan kendaraan Simpang klampis jaya - manyar tiap harinya.

Pengumpulan Data Sekunder. Data sekunder adalah data yang diperoleh secara tidak langsung dari instansi terkait. Data sekunder yang dibutuhkan untuk mendukung studi ini antara lain: Data jumlah kendaraan minimal 3 tahun terakhir; Data luasan Simpang Simpang klampis jaya - manya; Data Rencana Tata Ruang Wilayah (RTRW) Kota Surabaya dan Provinsi Jawa Timur. Tahap Kompilasi dan Analisis DataKompilasi. Data Kompilasi data merupakan tahap rekapitulasi data primer. Misal data primer berupa hasil pencacahan lalu lintas kendaraan, hasil kompilasi data lalu lintas berupa grafik fluktuasi volume lalu lintas kendaraan yang nantinya bisa digunakan sebagai dasar penentuan jam sibuk (peak hour). Volume lalu lintas saat jam sibuk akan menjadi dasar volume lalu lintas yang akan digunakan dalam analisis kinerja lalu lintas eksisting. 
Analisis Data Analisis Kinerja Lalu Lintas. Salah satu parameter yang dijadikan acuan untuk melaksanakan manajemen dan rekyasa lalu lintas adalah kinerja lalu lintas. Untuk kinerja lalu lintas yang dinilai adalah degree of saturation (=DS, derajad kejenuhan) pada ruas jalan dan simpang, serta besarnya delay (tundaan) dan queue (antrian) pada suatu simpang.

Dari skala waktu, analisis kinerja lalu lintas akan dilakukan 3 (tiga) skala waktu, yakni: Kineja lalu lintas eksisting; Kinerja lalu lintas setelah dilakukan peramalan sesuai angka pertumbuhan kendaraan tahun 2021 di Jalan Simpang Klampis Jaya - Manyar; Kinerja lalu lintas peramalan sesuai angka pertumbuhan kendaraan tahun 2021 di Jalan Simpang Klampis Jaya - Manyar.

Analisis Bangkitan Perjalanan. Metode untuk analisis kinerja lalu lintas dan tingkat pelayanan di simpang masuk simpang Jalan Simpang Klampis Jaya - Manyar menggunakan analisis regresi linear hubungan antara volume lalu lintas kendaraan yang keluar masuk suatu bangunan analog dengan beberapa variabel/parameter yang diduga mempengaruhi kinerja lalu lintas di Pelabuhan Tanjung Perak sebagai bangunan pelabuhan analog.

Analisis Pembebanan Lalu Lintas. Analisis pembebanan volume lalu lintas hasil kinerja lalu lintas kendaraan yang akan keluar masuk Simpang klampis jaya - manyar bertujuan untuk mengetahui seberapa besar volume kendaraan yang keluar masuk Simpang klampis jaya - manyar akan membebani ruas dan simpang di sekitar lokasi Simpang klampis jaya - manyar. Volume lalu lintas hasil pembebanan bangkitan kendaraan yang keluar masuk Simpang klampis jaya - manyar akan menjadi data masukkan volume lalu lintas untuk analisis kinerja lalu lintas saat beroperasinya Simpang klampis jaya - manyar dengan adanya pembebanan volume lalu lintas dari Simpang klampis jaya - manyar.

Manajemen dan Rekayasa Lalu Lintas di sekitar Simpang klampis jaya - manyar bertujuan untuk memperbaiki kinerja lalu lintas di beberapa ruas jalan dan simpang di sekitar Simpang klampis jaya - manyar. Untuk usaha manajemen dan rekayasa lalu lintas di sekitar Simpang klampis jaya - manyar dilakukan berdasarkan skala waktu. Pembagian skala waktu pelaksanaan manajemen lalu lintas adalah sebagai berikut: Seketika/mendesak; Perbaikan yang dilakukan adalah perbaikan kontrol yang ada (persimpangan, parkir dll); Jangka Pendek.

Dilakukannya perubahan arus lalu lintas dengan manajemen lalu lintas dan sarana penunjang lainnya Jangka Menengah. Melakukan peningkatan kapasitas jaringan jalan dan perubahan arus lalu lintas, pelebaran jalan dan konstruksi jalan baru

Jangka Panjang melakukan perubahan arus lalu lintas berdasarkan pertumbuhan arus lalu lintas dengan mengontrol pengembangan rencana perkotaan.

\section{Prosedur Penelitian}

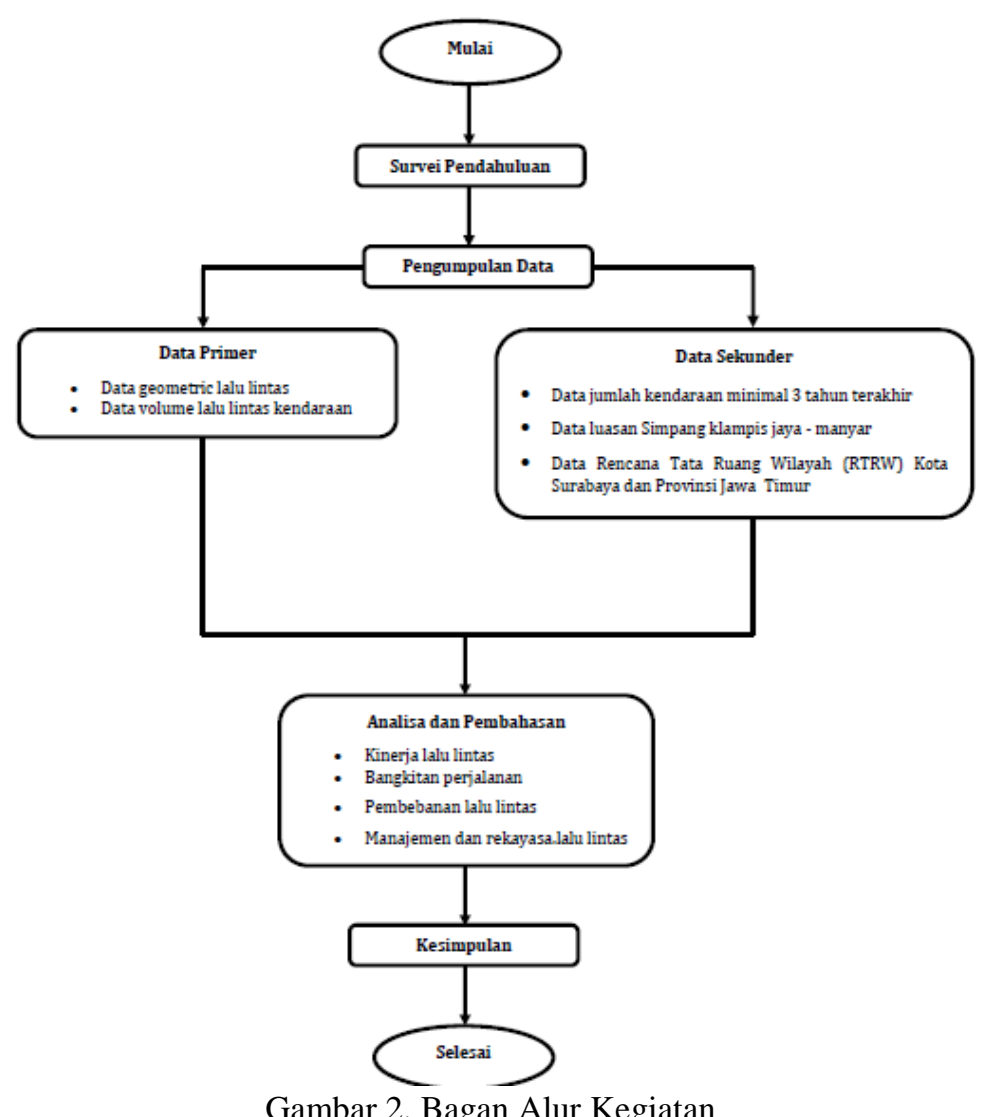

Proceedings homepage: https://conferenceproceedings.ump.ac.id/index.php/pspfs/issue/view/8 


\section{HASIL DAN PEMBAHASAN}

Input data adalah dapat berupa data primer yang didapatkan dari hasil survey pada lokasi penelitian. Penginputan data ini terdiri atas dasar kondisi geometrik, data survey dan data kondisi lingkungan. Data masukan diperlukan dalam proses analisa data dan analisa kinerja simpang tak bersinyal Jalan Klampis Jaya.

Tabel 1. Volume Total Kendaraan

\begin{tabular}{|c|c|c|c|c|c|}
\hline & \multicolumn{2}{|l|}{ Waktu } & \multicolumn{3}{|c|}{ JUMLAH TIAP JAM } \\
\hline & & & $\mathrm{MC}$ & $\mathrm{LV}$ & $\mathrm{HV}$ \\
\hline & 17.00 & - & & & \\
\hline 18.00 & & & 712 & 241 & - \\
\hline & 17.15 & - & & & \\
\hline 18.15 & & & 693 & 245 & - \\
\hline & 17.30 & - & & & \\
\hline 18.30 & & & 666 & 214 & - \\
\hline & 17.45 & - & & & \\
\hline 18.45 & & & 665 & 276 & - \\
\hline & 18.00 & - & & & \\
\hline 19.00 & & & 775 & 248 & - \\
\hline
\end{tabular}

Sumber: Hasil Survei

Tahun 2018 ke tahun 2021 nilai derajat kejenuhan (DS) keempat simpang meningkat di akibatkan pertumbuhan arus lalu-lintas kendaraan normal ditambah dengan kendaraan akibat pembangunan saluran. Untuk lebih jelasnya perbandingan kinerja lalu-lintas tiap simpang disampaikan pada tabel berikut:

Tabel 2. Total Volume Kendaraan Tahun 2018 - 2021

\begin{tabular}{cllll}
\hline Jenis Kendaraan & 2018 & 2019 & 2020 & 2021 \\
\hline LV (Sedan) & 48258 & 47459 & 50164 & 53024 \\
HV (Bus) & 2304 & 2486 & 2628 & 2777 \\
MC (Sepeda & & & & \\
Motor) & 1274660 & 669341 & 1482115 & 1566595 \\
\hline
\end{tabular}

Sumber: Hasil Pengolahan Data

Tabel 3. Perbandingan Kondisi Volume Lalu Lintas Jalan Klampis Jaya

\begin{tabular}{ccc}
\hline Tahun & Derajat Kejenuhan (DS) & Tingkat Pelayanan \\
\hline 2021 & 0,752 & $\mathrm{C}$ \\
2024 & 0,95 & $\mathrm{D}$ \\
\hline \multicolumn{3}{c}{}
\end{tabular}

Sumber: Hasil Pengolahan Data

Dari tabel 3 menunjukkan bahwa pada kondisi exsisting simpang Jalan Klampis Jaya memiliki DS sebesar 0,752 dengan tingkat pelayanan C (Cukup). Dari hasil tersebut menunjukkan bahwa kondisi exsisting persimpangan Jalan Klampis Jaya sudah cukup padat . Dan untuk hasil peramalan volume lalu lintas pada tahun 2024 simpang Jalan Klampis Jaya memiliki DS sebesar 0,95 dengan tingkat pelayanan D (Kurang). Artinya perlu dilakukan manajemen lalu lintas atau pelebaran jalan.

\section{KESIMPULAN}

Pada survey simpang bersinyal akan diketahui perilaku lalu lintas pada sebuah persimpangan. Pada survey simpang tak bersinyal yang kami lakukan di persimpangan Klampis Jaya, dengan melihat nilai jumlah kendaraan, dapat disimpulkan bahwa pada persimpangan Klampis Jaya tergolong ramai lancar pada saat jam pulang kerja. Hal tersebut bisa dilihat dari jumlah kendaraan yang melintas. Hasil perhitungan kinerja lalu-lintas keempat simpang di Klampis Jaya menunjukkan Derajat Kejenuhan (DS), dan Tingkat Pelayanan (TP) tiap simpang dan kinerja lalu-lintas untuk keempat lengan simpang pada tahun 2021 adalah DS =0,752 dan TP $=\mathrm{C}$ (Cukup), dengan ciri-ciri lalu lintas arus stabil pergerakan dibatasi. Kinerja lalu-lintas untuk keempat simpang pada tahun 2024 adalah DS = 0,95 dan TP $=\mathrm{D}$ (Kurang), dengan ciri-ciri lalu lintas arus stabil pergerakan dibatasi.

\section{UCAPAN TERIMA KASIH}

Dalam penyusunan jurnal ini tidak terlepas dukungan dari berbagai pihak. Penulis secara khusus mengucapkan terimakasih yang sebesar-besarnya kepada pihak yang telah membantu. Pada kesempatan ini penulis menyampaikan rasa terimakasih yang sebesar-besarnya kepada : 
Allah Subhanahuwa Ta'ala dengan segala Rahmat dan Karunia-Nya yang memberikan kekuatan bagi peneliti dalam menyelesaikan jurnal ini. Anita Susanti, SPd.,M.T, selaku Ketua Program Studi Teknologi Rekayasa Transportasi Universitas Negeri Surabaya. Kepada kedua orang tua tercinta Bapak dan Ibu tercinta, yang selama ini telah membantu penulis dalam bentuk perhatian, kasih sayang, serta do'a yang tidak henti-hentinya demi kelancaran dan kesuksesan penulis dalam menyelesaikan jurnal. Segenap dosen dan staff akademik yang selalu membantu memberikan fasilitas, ilmu, serta pendidikan pada penulis hingga dapat menunjang dalam menyelesaikan jurnal ini.

\section{DAFTAR PUSTAKA}

Anonim, 1, Manual Kapasitas Jalan Indonesia (MKJI). (1997). Direktorat Jenderal Bina Marga, Departemen Pekerja Umum Jakarta.

Badan Pusat Statistik. (2019). Surabaya Dalam Angka. Badan Pusat Statistik Kota Surabaya.

McShane, William R. \& Roess, Roger P. (1990). Traffic Engineering. Pearson Higher Education, Inc. New Jersey.

Miro, Fidel. (2004). Perencanaan Transportasi Untuk Perencana dan Praktisi. Erlangga. Jakarta.

Tamin, 2000, "Perencanaan dan Pemodelan Transportasi”, ITB, Bandung

Taylor, M.A.P., Young, W. \& Bonsall, P.W. (2000). Understanding Traffic System: Data, Analysis and Presentation. Second Edition. Athenaeum Press Ltd. Gateshead, Tyne and Wear. England.

Transportation Research Board. (2010). Highway Capacity Manual 2010. Washington: TRB of National Academies.

Wibisono, R Endro., Muhtadi, A., \& Cahyono MSD. (2019). Kajian Analisis Lalulintas Simpang Bersinyal di By Pass Krian Untuk Perencanaan Pelebaran Jalan dan Fly Over. Ge-STRAM: Jurnal Perencanaan dan Rekayasa Sipil, Vol.02, No.01, Maret 2019, hal : 9-15

Wibisono, R Endro. \& Cahyono MSD. (2018). Kinerja Lalu-lintas Simpang di Kalen-Majenang Akibat Pembangunan Saluran Irigasi Waduk Kalen di Kecamatan Kedungpring Kabupaten Lamongan. Jurnal Manajemen Aset Infrastruktur \& Fasilitas, Vol.2, No.2, September 2018, hal: 117-128.

Wibisono, E. (2020). “Analisa Dampak Lalu Lintas Jalan Tambak Osowilangun Akibat Pembangunan Teluk Lamong Surabaya”. UKaRsT 4 Vol.4, No.1, Maret 2020, hal : 69-83

Wibisono, R Endro., \& Mahardi, Purwo. (2020). Analysis on Calculation of Vehicle Operating Cost (VOC) Before and After Flyover \& Road Widening Operation at Gedangan Intersection in Sidoarjo Regency. Journal of Physics: Conference Series, Vol. 1569 No.4, 2020, 042017. 